\title{
Cucurbitacin $\mathbf{E}$ induces apoptosis of human prostate cancer cells via cofilin-1 and mTORC1
}

\author{
XIAOLONG HE, QI GAO, YAYONG QIANG, WEI GUO and YADONG MA \\ Department of Urology, Yan'an University Affiliated Hospital, Yan'an, Shaanxi 716000, P.R. China
}

Received July 12, 2015; Accepted October 21, 2016

DOI: $10.3892 / 01.2017 .6086$

\begin{abstract}
Cucurbitacin E is an important member of the cucurbitacin family and exhibits inhibitory effects in various types of cancer. Cucurbitacin is a potential antineoplastic drug; however, its anticancer effect in human prostate cancer (PC) remains unknown. The aim of the present study was to determine whether the effect of cucurbitacin $\mathrm{E}$ on the cell viability and apoptosis of the human PC cell line, LNCaP, was mediated by cofilin-1- and mammalian target of rapamycin (mTOR). The results of the present study demonstrated that cucurbitacin E significantly exhibited cytotoxicity, suppressed cell viability $(\mathrm{P}<0.0001)$ and induced apoptosis $(\mathrm{P}=0.0082)$ in LNCaP cells. In addition, it was demonstrated that treatment with cucurbitacin E significantly induced cofilin-1 ( $\mathrm{P}=0.0031)$, p-mTOR $(\mathrm{P}=0.0022)$, AMP-activated protein kinase (AMPK; $\mathrm{P}=0.0048)$, cellular tumor antigen $\mathrm{p} 53$ (p53; $\mathrm{P}=0.0018)$ and caspase-9 $(\mathrm{P}=0.0026)$ protein expression in LNCaP cells, suggesting that cucurbitacin E exerts its effects on LNCaP cells through cofilin-1, mTOR, AMPK, p53 and caspase-9 signaling. These results suggested that cucurbitacin $\mathrm{E}$ maybe used as a therapeutic agent in the treatment of human PC.
\end{abstract}

\section{Introduction}

Prostate cancer (PC) is a type of malignant cancer that affects male prostate tissue, and is a result of abnormal and disordered acinar cell growth (1). Currently, PC is the second most frequently observed cancer worldwide and its morbidity rate is increasing annually (2). According to the World Health Organization (WHO), there were 899,000 new PC cases in 2008, which accounted for $\sim 14 \%$ of new cancer cases in men worldwide (3). According to a prediction by the WHO, the number of patients with PC will have increased to 1.7 million

Correspondence to: Dr Yadong Ma, Department of Urology, Yan'an University Affiliated Hospital, 43 North Street, Yan'an, Shaanxi 716000, P.R. China

E-mail: yadongmayd@163.com

Key words: cucurbitacin E, human prostate cancer, cofilin-1, mammalian target of rapamycin, AMP-activated protein kinase, cellular tumor antigen p53 by 2030 (4). Epidemiological studies have reported that the morbidity rate of PC is dependent on geography and ethnicity, and is more prevalent in developed countries $(5,6)$.

Cofilin-1 is an actin-associated protein with a low molecular weight that is present in eukaryotic cells (7). The genes encoding cofilin-1 are located on chromosome 11q13 and are expressed in various types of non-muscle tissue, including the liver and brain (8). The remodeling of the actin cytoskeleton serves an important role in the processes of invasion and metastasis of cancer cells (9). The regulation of actin and actin-associated proteins, includingcofilin-1, is important in the formation of pseudopodium (8). Cofilin-1 is an essential regulatory factor for cancer cell metastasis and invasion, and its overexpression leads to increased cancer cell migration (10). Therefore, cofilin-1 inhibition may significantly reduce the invasiveness of cancer cells (11). In melanoma cells, exogenous cofilin-1 signaling may upregulate the expression of matrix metalloproteinases 2 and 14 (11). Cofilin-1 is therefore able to promote matrix degradation, facilitating pseudopodium-mediated invasion.

Mammalian target of rapamycin (mTOR) is an important signal transduction molecule, which regulates transcription and translation through the integration of extracellular signals (12). mTOR complex 1 (mTORC1) is the primary form of mTOR and has an important role in cell growth, proliferation, differentiation and apoptosis (12-14). mTORC1 consists of mTOR, TORC subunit LST8 and regulatory-associated protein of mTOR (RPTOR) (14). A previous study demonstrated that the dysregulation of elements of the mTOR signaling pathway was associated with the occurrence, development and metastasis of various types of cancer (15).

Cucurbitacin $\mathrm{E}$ is a member of the cucurbitacin family, which are a group of tetracyclic triterpenoids extracted from cucurbitaceous plants (16). Studies have demonstrated that cucurbitacin E possesses a number of pharmacological functions, including anticancer, anti-viral and anti-inflammatory effects $(17,18)$. Cucurbitacin $\mathrm{E}$ is able to inhibit the activation of signal transducer and activator of transcription 3 (STAT3)-associated transcription factors, and disrupt the mitogen-activated protein kinase signaling pathway (19). Cucurbitacin E induces G2/M cell cycle arrest and apoptosis in cancer cells, and subsequent cytoskeletal changes (17). Therefore, the present study aimed to investigate whether cucurbitacin E induces the apoptosis of human PC through cofilin-1 and mTORC1 signaling. 


\section{Materials and methods}

Materials. Cucurbitacin E was obtained from Sigma-Aldrich (Merck Millipore, Darmstadt, Germany) and its formula is shown in Fig. 1. Dimethyl sulfoxide (DMSO), SDS, MTT and lactate dehydrogenase (LDH) were also obtained from Sigma-Aldrich (Merck Millipore). Dulbecco's modified Eagle's medium (DMEM), fetal bovine serum (FBS), penicillin and streptomycin were obtained from Thermo Fisher Scientific, Inc. (Waltham, MA, USA). The Cell Death Detection ELISA kit was obtained from Roche Diagnostics (Indianapolis, IN, USA). Polyvinylidene difluoride (PVDF) membranes were obtained from GE Healthcare Life Sciences (Chalfont, UK).

Cell culture. The human PC cell line, LNCaP, was obtained from the Experiment Center of Yan'an University (Yan'an, China), and cultured in DMEM supplemented with $10 \% \mathrm{FBS}, 100 \mathrm{U} / \mathrm{ml}$ penicillin and $100 \mu \mathrm{g} / \mathrm{ml}$ streptomycin. Cells were incubated at $37^{\circ} \mathrm{C}$ in a humidified atmosphere containing $5 \% \mathrm{CO}_{2}$.

Cell viability assay. Cell viability was determined using the MTT assay, as previously described (15). Briefly, LNCaP cells were seeded in 96-well plates at a density of 3,300 cells/well and incubated overnight at $37^{\circ} \mathrm{C}$, prior to treatment with 0 , $0.01,0.1,1,10$ and $100 \mu \mathrm{M}$ cucurbitacin E. At 24 and $48 \mathrm{~h}$ following treatment with cucurbitacin E, $20 \mu \mathrm{l}$ MTT solution $(0.1 \mathrm{mg} / \mathrm{ml})$ was added to the cells and the plates were subsequently incubated at $37^{\circ} \mathrm{C}$ for $4 \mathrm{~h}$. Following incubation, $150 \mu \mathrm{l}$ DMSO was added for 20 min to dissolve the formazan crystals. The absorbance at $570 \mathrm{~nm}$ was measured using a microplate reader (BioTek Instruments, Inc., Winooski, VT, USA) and the cell viability was subsequently calculated using the following

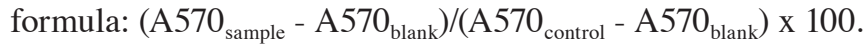

Cytotoxicity assay. Cytotoxicity was determined using the LDH assay, as previously described (15). Briefly, LNCaP cells were seeded in 96-well plates at a density of 3,300 cells/well and incubated overnight at $37^{\circ} \mathrm{C}$ prior to treatment with $0,0.1$, 1 and $10 \mu \mathrm{M}$ cucurbitacin E. After $24 \mathrm{~h}, 100 \mu \mathrm{LDH}$ solution was added to the cells and the plates were incubated at $37^{\circ} \mathrm{C}$ for $30 \mathrm{~min}$. The absorbance at $490 \mathrm{~nm}$ was measured using a microplate reader.

Detection of apoptosis. LNCaP cells were seeded into 6-well plates at a density of $1 \times 10^{5}$ cells/well, in triplicate, prior to treatment with $0,0.1,1$ and $10 \mu \mathrm{M}$ cucurbitacin $\mathrm{E}$ for $24 \mathrm{~h}$. Apoptotic nucleosomes were measured using the Cell Death Detection kit (KeyGen, Shanghai, China) with $10 \mu \mathrm{g}$ Annexin $\mathrm{V}$-fluorescein isothiocyanate and $5 \mu \mathrm{g}$ propidium iodide for $15 \mathrm{~min}$ in darkness according to the manufacturer's protocol. Apoptosis rate was analyzed by flow cytometry (Epics XL Flow Cytometer; Beckman Coulter, Inc., Brea, CA, USA). The data were analyzed using the ModFit LT program (Verity Software House, Topsham, ME, USA).

Western blot analysis. LNCaP cells were seeded into 6-well plates at a density of $1 \times 10^{5}$ cells/well, in triplicate, prior to treatment with $0,0.1,1$ and $10 \mu \mathrm{M}$ cucurbitacin $\mathrm{E}$ for $24 \mathrm{~h}$. Cells were lysed on ice in radioimmunoprecipitation assay lysis buffer (Beyotime Institute of Biotechnology, Haimen,

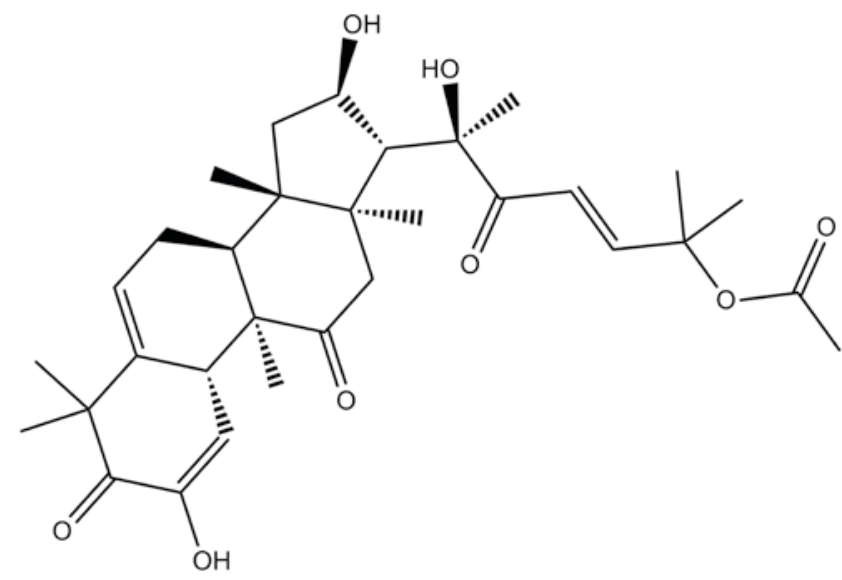

Figure 1. Chemical structure of cucurbitacin E.

China) and homogenized. Total protein concentration was subsequently assessed using a Bradford Assay kit (Beyotime Institute of Biotechnology). Equal amounts of protein $(50 \mu \mathrm{g})$ were resolved on a $12 \% \mathrm{w} / \mathrm{v}$ gel using SDS-PAGE and transferred onto a PVDF membrane. The membrane was blocked using 5\% milk in TBS containing Tween-20 at $37^{\circ} \mathrm{C}$ for $1 \mathrm{~h}$ and incubated with the following primary antibodies overnight at $4^{\circ} \mathrm{C}$ : Mouse anti-cofilin-1 (1:500, sc-53934); mouse phosphorylated (p)-anti-mTOR (1:500, sc-293132); anti-AMP-activated protein kinase (AMPK) (1:400, sc-25792); mouseanti-P53 (1:2,000; sc-6243), mouse anti-caspase-9 (1:400, sc-47698; all Santa Cruz Biotechnology, Inc., Dallas, TX, USA) and mouse anti- $\beta$-actin (AF0003, 1:500; Beyotime Institute of Biotechnology). The membrane was then incubated with horseradish peroxidase-conjugated goat anti-rabbit or anti-mouse secondary antibodies (40,000, A0208 or A02581; Beyotime Institute of Biotechnology) for $2 \mathrm{~h}$ at room temperature. $\beta$-actin was used as the loading control. Protein bands were visualized using New-SUPER ECL (cat. no. KGP1127; Nanjing KeyGen Biotech Co., Ltd., Nanjing, China) and the band intensity was quantified using ImageJ software (version 3.0; National Institutes of Health, Bethesda, MA, USA).

Statistical analysis. Values are presented as the mean \pm standard error of the mean. Statistical analysis was performed using GraphPad Prism 4.0 (GraphPad Software Inc., La Jolla, CA, USA), and the results were analyzed using analysis of variance and the Bonferroni post hoc test. $\mathrm{P}<0.05$ was considered to indicate a statistically significant difference.

\section{Results}

Treatment with cucurbitacin E suppresses LNCaP cell viability. The MTT assay was performed to demonstrate that treatment with cucurbitacin E reduces the viability of human PC cells. Treatment with cucurbitacin E was shown to suppress LNCa cell viability in a dose- and time-dependent manner (Fig. 2). Treatment with 10 and $100 \mu \mathrm{M}$ cucurbitacin $\mathrm{E}$ for $24 \mathrm{~h}$ significantly decreased LNCaP cell viability compared with the untreated cells $(\mathrm{P}=0.0092$ and 0.0081 , respectively; Fig. 2A). Treatment with 0.1-100 $\mu \mathrm{M}$ cucurbitacin $\mathrm{E}$ for $48 \mathrm{~h}$ significantly decreased LNCaP cell viability compared with 

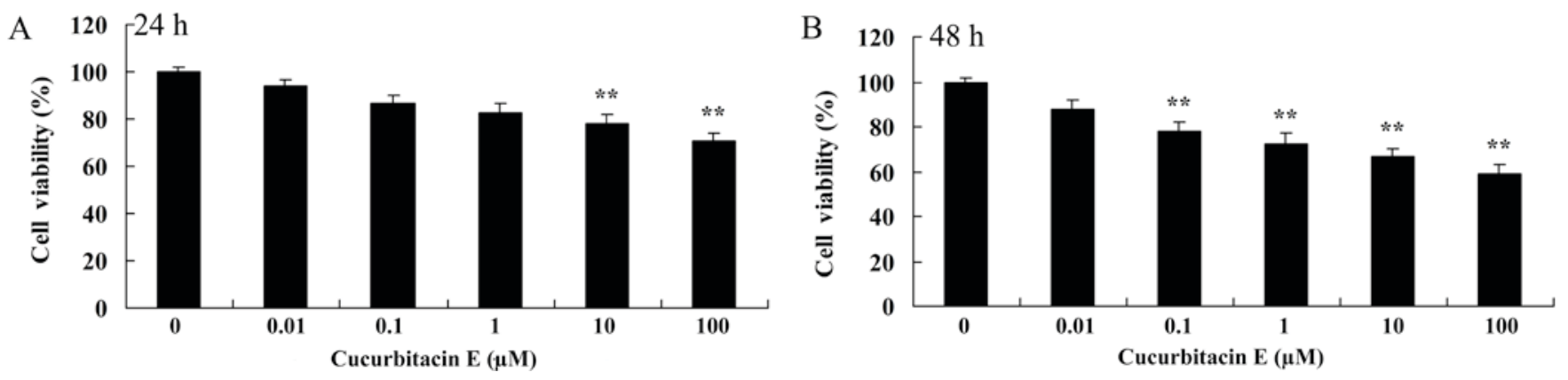

Figure 2. Treatment with cucurbitacin E suppresses LNCaP cell viability. Cell viability was evaluated using the MTT assay at (A) 24 and (B) 48 h following treatment with cucurbitacin $\mathrm{E} .{ }^{* *} \mathrm{P}<0.01$ vs. untreated cells.

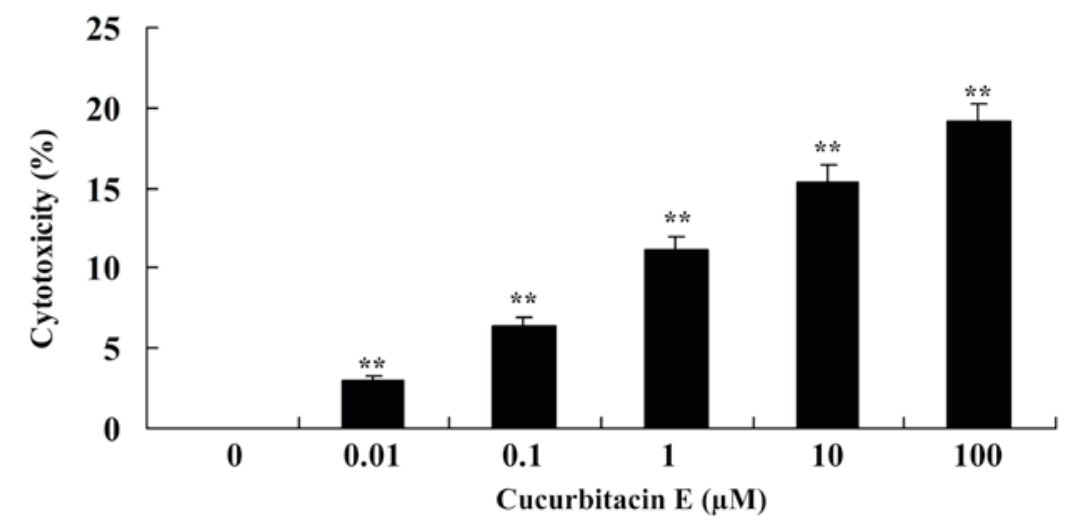

Figure 3. Cucurbitacin E exhibits cytotoxicity in LNCaP cells. ${ }^{* *} \mathrm{P}<0.01$ vs. untreated cells.

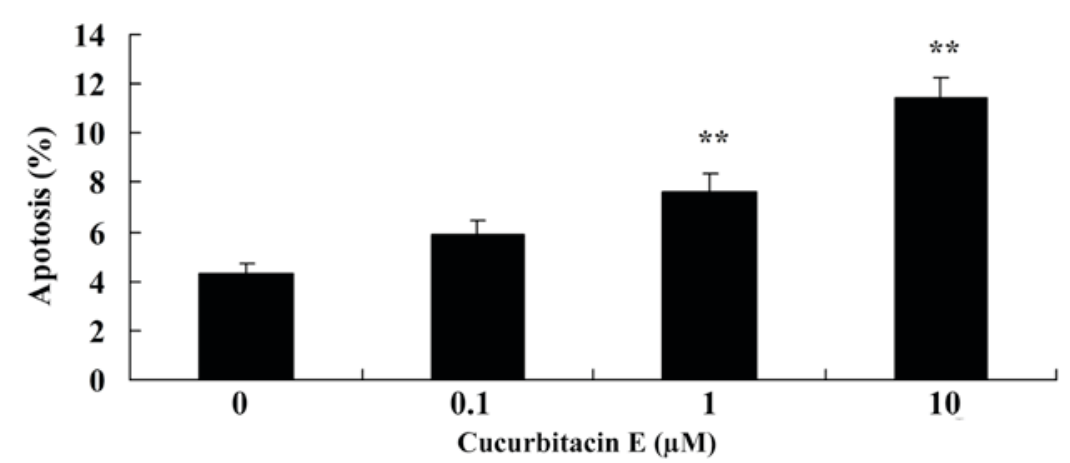

Figure 4. Treatment with cucurbitacin E induces apoptosis in LNCaP cells. ${ }^{* *} \mathrm{P}<0.01$ vs. untreated cells.

the untreated cells $(\mathrm{P}=0.0079,0.0063,0.0055$ and 0.0041 for $0.1,1,10$ and $100 \mu \mathrm{M}$, respectively; Fig. 2B).

Cucurbitacin E exhibits cytotoxicity in LNCaP cells. The LDH assay was performed to analyze the cytotoxicity of cucurbitacin E on human PC cells. Cucurbitacin E significantly exhibited marked cytotoxicity on LNCaP cells in a dose-dependent manner $(\mathrm{P}=0.00092,0.0079,0.0065,0.0050$ and 0.00021 for $0.01,0.1,1,10$ and $100 \mu \mathrm{M}$, respectively; Fig. 3).

Treatment with cucurbitacin E induces apoptosis of LNCaP cells. The Cell Death Detection ELISA kit was used to measure the effect of cucurbitacin E on the apoptosis of human PC cells. Treatment with 1 and $10 \mu \mathrm{M}$ cucurbitacin $\mathrm{E}$ for $24 \mathrm{~h}$ led to significantly increased apoptosis in LNCaP cells, as compared with the untreated cells $(\mathrm{P}=0.0076$ and 0.0045 , respectively; Fig. 4).

Treatment with cucurbitacin E induces cofilin-1 protein expression. The effect of treatment with $0,0.1,1$ and $10 \mu \mathrm{M}$ cucurbitacin $\mathrm{E}$ for $24 \mathrm{~h}$ on cofilin-1 protein expression in LNCaP cells was evaluated. Cofilin-1 protein expression was significantly increased following treatment with 1 and $10 \mu \mathrm{M}$ cucurbitacin E compared with the untreated cells $(\mathrm{P}=0.0076$ and 0.0045, respectively; Fig. 5A and B).

Treatment with cucurbitacin E induces mTOR protein expression. To determine whether the induction of cofilin-1 expression impacted on the expression of other proteins, mTOR protein expression was evaluated using western blotting. mTOR protein 
A

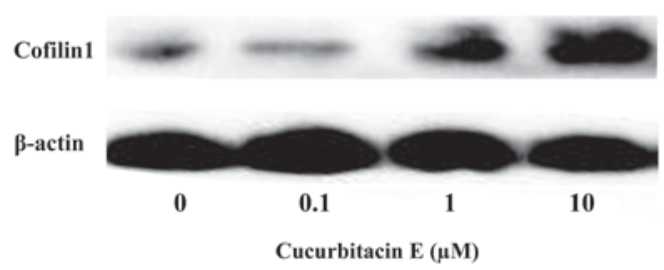

B

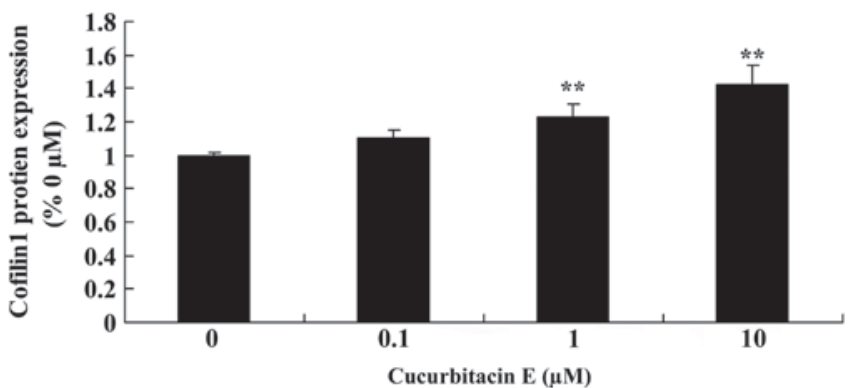

Figure 5. Treatment with cucurbitacin E induces cofilin-1 protein expression. (A) Western blot analysis demonstrated increased cofilin-1 protein expression following treatment with cucurbitacin E. (B) This was confirmed by protein band quantification relative to cofilin-1 expression in the untreated cells. ${ }^{* *} \mathrm{P}<0.01$ vs. untreated cells.
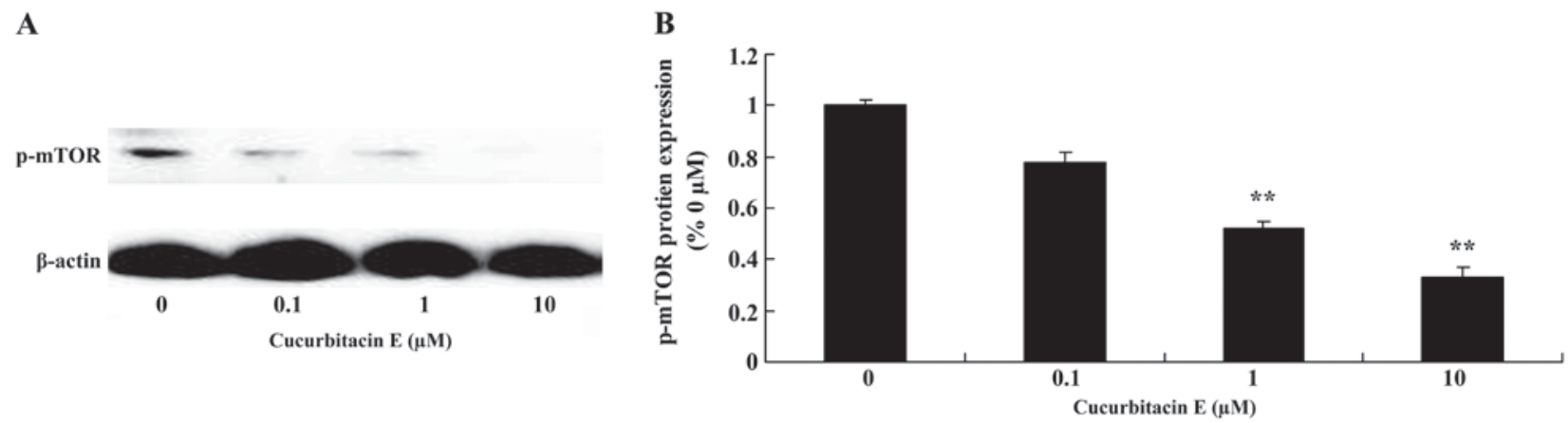

Figure 6. Treatment with cucurbitacin E induces mTOR protein expression. (A) Western blot analysis demonstrated increased mTOR protein expression following treatment with cucurbitacin E. (B) This was confirmed by protein band quantification relative to mTOR expression in the untreated cells. ${ }^{* * *} \mathrm{P}<0.01$ vs. untreated cells. mTOR, mammalian target of rapamycin.

A

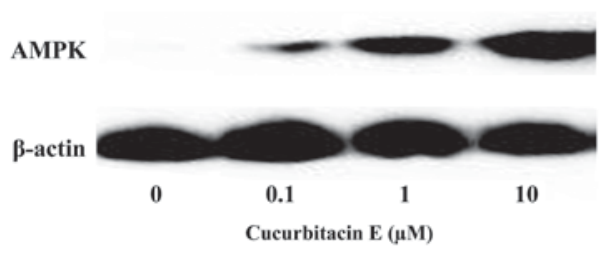

B

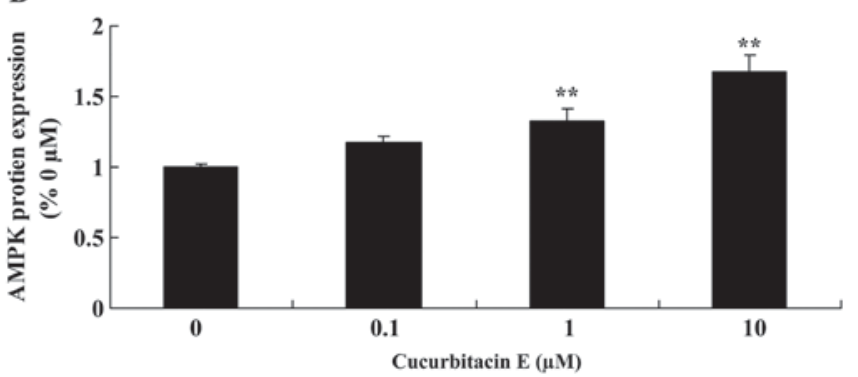

Figure 7. Treatment with cucurbitacin E induces AMPK protein expression. (A) Western blot analysis demonstrated increased AMPK protein expression following treatment with cucurbitacin E. (B) This was confirmed by protein band quantification relative to AMPK expression in the untreated cells. ${ }^{* *} \mathrm{P}<0.01$ vs. untreated cells. AMPK, AMP-activated protein kinase.
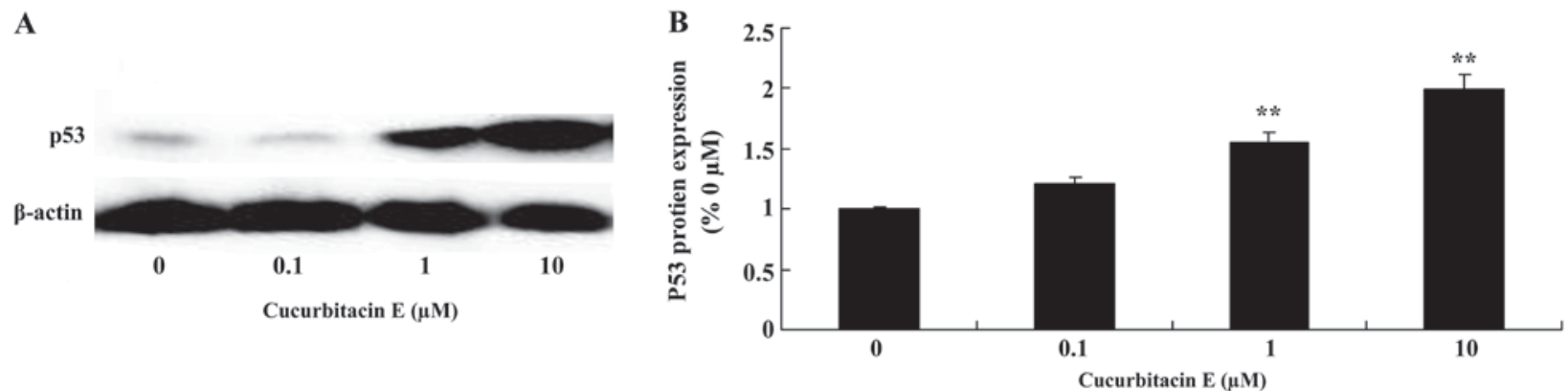

Figure 8. Treatment with cucurbitacin E induces p53 protein expression. (A) Western blot analysis demonstrated increased p53 protein expression following treatment with cucurbitacin E. (B) This was confirmed by protein band quantification relative to p53 expression in the untreated cells. ${ }^{* *} \mathrm{P}<0.01$ vs. untreated cells. p53, cellular tumor antigen p53. 
A

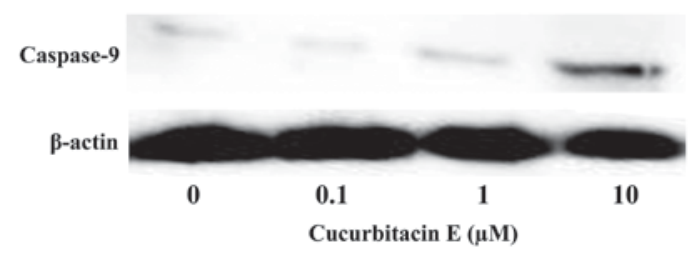

B

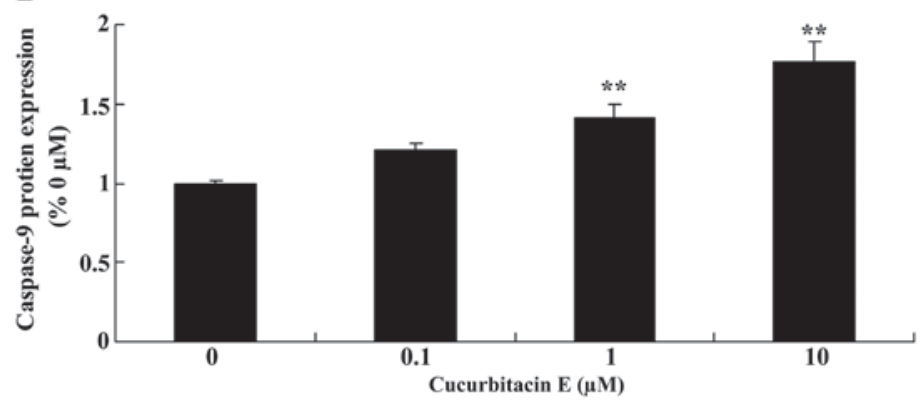

Figure 9. Treatment with cucurbitacin E induces caspase-9 protein expression. (A) Western blot analysis demonstrated increased caspase-9 protein expression following treatment with cucurbitacin $\mathrm{E}$. (B) This was confirmed by protein band quantification relative to caspase- 9 expression in the untreated cells. ${ }^{* *} \mathrm{P}<0.01$ vs. untreated cells.

expression was significantly increased following treatment with 1 and $10 \mu \mathrm{M}$ cucurbitacin E compared with the untreated cells $(\mathrm{P}=0.0030$ and 0.0009 , respectively; Fig. $6 \mathrm{~A}$ and $\mathrm{B})$.

Treatment with cucurbitacin E induces AMPK protein expression. To determine changes in the expression of apoptotic proteins in LNCaP cells following treatment with cucurbitacin E, AMPK protein expression was evaluated using western blotting. AMPK protein expression was significantly increased following treatment with 1 and $10 \mu \mathrm{M}$ cucurbitacin E compared with the untreated cells $(\mathrm{P}=0.0011$ and $\mathrm{P}<0.0001$, respectively; Fig. 7A and $\mathrm{B}$ ).

Treatment with cucurbitacin $E$ induces $p 53$ protein expression. The effect of treatment with $0,0.1,1$ and $10 \mu \mathrm{M}$ cucurbitacin $\mathrm{E}$ for $24 \mathrm{~h}$ on $\mathrm{p} 53$ protein expression in $\mathrm{LNCaP}$ cells was evaluated. p53 protein expression was significantly increased following treatment with 1 and $10 \mu \mathrm{M}$ cucurbitacin E compared with the untreated cells $(\mathrm{P}=0.0021$ and $\mathrm{P}<0.0001$, respectively; Fig. 8A and $\mathrm{B}$ ).

Treatment with cucurbitacin E inducescaspase-9 protein expression. The effect of treatment with $0,0.1,1$ and $10 \mu \mathrm{M}$ cucurbitacin $\mathrm{E}$ for $24 \mathrm{~h}$ on caspase- 9 protein expression in LNCaP cells was evaluated. Caspase-9 protein expression was significantly increased following treatment with 1 and $10 \mu \mathrm{M}$ cucurbitacin $\mathrm{E}$ compared with the untreated cells $(\mathrm{P}=0.0050$ and 0.0023, respectively; Fig. 9A and B).

\section{Discussion}

$\mathrm{PC}$ is the most frequently occurring cancer in Western countries and a primary cause of cancer-associated mortality (4). Although castration is effective in patients with early stage PC, other therapeutic regimes are limited by the development of hormonal-refractory or hormone-resistant PC (20). The present study demonstrated that cucurbitacin E exerted cytotoxic effects on LNCaP cells, decreasing the cell viability and inducing apoptosis. Previous studies demonstrated that treatment with cucurbitacin $\mathrm{E}$ induced apoptosis in triple-negative breast cancer, ovarian cancer and PC cells (21-23).

Cofilin-1 is a low molecular weight polypeptide expressed universally in eukaryotes (9). Cofilin-1 expression has been shown to be dysregulated in various types of cancer tissue, including bladder, breast and esophageal cancer, and affects the occurrence, progression, diagnosis, prognosis and treatment of cancer (8). The results of the present study demonstrated that treatment with cucurbitacin $\mathrm{E}$ induced cofilin-1 protein expression in LNCaP cells. Nakashima et al (24) suggested that cucurbitacin E inhibits cofilin-1 phosphorylation in human leukemia cells.

mTORC1 is an important regulatory factor of cell growth, proliferation and cell cycle progression by regulating the phosphorylation of its downstream proteins (25). RPTOR interacts with mTOR and mediates trophic signal transduction to regulate cell size and mTOR-associated protein expression (26). The mTOR signaling pathway is an important signaling pathway; its overactivation is able to promote the growth and proliferation of cancer cells, inhibit apoptosis and autophagy, and promote cell migration, invasion, metastasis and angiogenesis (27). mTOR is closely associated with the genesis and development of cancer. Previous studies have demonstrated that mTOR protein expression is significantly upregulated in various types of cancer tissue, including PC, liver cancer, cervical cancer, colorectal cancer, lung adenocarcinoma, esophageal squamous carcinoma, non-small cell lung cancer and extra hepatic bile duct carcinoma $(25,28)$. The results of the present study demonstrated that treatment with cucurbitacin E induced mTOR protein expression inhuman PC cells. Zha et al (29) suggested that cucurbitacin E induces autophagy through AMPK and mTORC1 signaling.

AMPK regulates the formation of the apoptosome through activation of the p53 signaling pathway and caspase-9 precursors (26). AMPK activates a number of proteases and endonucleases, and inhibits DNA repairase, which leads to the damage of cytoskeletal proteins and nucleoproteins, and subsequent apoptosis (30). The results of the present study demonstrated that treatment with cucurbitacin $\mathrm{E}$ induced AMPK, p53 and caspase-9 protein expression in LNCaP cells. Sun et al (31) reported that cucurbitacin E treatment may be effective against pancreatic cancer by activating p53 and STAT3 signaling. Huang et al (18) demonstrated that treatment with cucurbitacin E induced G2/M cell cycle arrest through the activation of caspase-8 and -9 . The present study demonstrated that treatment with cucurbitacin E induced apoptosis in human PC cells via cofilin-1 and mTORC1 signaling. These results suggested that cucurbitacin E may be a potential therapeutic candidate for the treatment of PC. 


\section{References}

1. Sidaway P: Prostate cancer: New biomarker panel prognosticates patient survival. Nat Rev Clin Oncol 12: 310, 2015.

2. Lee BH, Kibel AS, Ciezki JP, Klein EA, Reddy CA, Yu C, Kattan MW and Stephenson AJ: Are biochemical recurrence outcomes similar after radical prostatectomy and radiation therapy? Analysis of prostate cancer-specific mortality by nomogram-predicted risks of biochemical recurrence. Eur Urol 67: 204-209, 2015

3. Chambers SK, Newton RU, Girgis A, Nielsen L, Lepore S, Mihalopoulos C, Gardiner R, Galvão DA and Occhipinti S: Living with prostate cancer: Randomised controlled trial of a multimodal supportive care intervention for men with prostate cancer. BMC Cancer 11: 317, 2011

4. Kawakami J, Cowan JE, Elkin EP, Latini DM, DuChane J and Carroll PR; CaPSURE Investigators: Androgen-deprivation therapy as primary treatment for localized prostate cancer: Data from cancer of the prostate strategic urologic research endeavor (CaPSURE). Cancer 106: 1708-1714, 2006.

5. Habl G, Uhl M, Katayama S, Kessel KA, Hatiboglu G, Hadaschik B, Edler L, Tichy D, Ellerbrock M, Haberer T, et al: Acute toxicity and quality of life in patients with prostate cancer treated with protons or carbon ions in a prospective randomized phase II Study-The IPI Trial. Int J Radiat Oncol Biol Phys 95: 435-443, 2016.

6. Petersen SE, Bentzen L, Emmertsen KJ, Laurberg S, Lundby L and Hoyer M: Development and validation of a scoring system for late anorectal side-effects in patients treated with radiotherapy for prostate cancer. Radiother Oncol 111: 94-99, 2014

7. Zhu B, Fukada K, Zhu H and Kyprianou N: Prohibitin and cofilin are intracellular effectors of transforming growth factor beta signaling in human prostate cancer cells. Cancer Res 66: 8640-8647, 2006.

8. Lu LI, Fu NI, Luo XU, Li XY and Li XP: Overexpression of cofilin 1 in prostate cancer and the corresponding clinical implications. Oncol Lett 9: 2757-2761, 2015.

9. Sundram V, Chauhan SC, Ebeling M and Jaggi M: Curcumin attenuates $\beta$-catenin signaling in prostate cancer cells through activation of protein kinase D1. PLoS One 7: e35368, 2012.

10. Dang D, Bamburg JR and Ramos DM: Alphavbeta3 integrin and cofilin modulate K1735 melanoma cell invasion. Exp Cell Res 312: 468-477, 2006.

11. Wang Z, Li Y, Banerjee S, Kong D, Ahmad A, Nogueira V, Hay N and Sarkar FH: Down-regulation of Notch-1 and Jagged-1 inhibits prostate cancer cell growth, migration and invasion, and induces apoptosis via inactivation of Akt, mTOR, and NF-kappaB signaling pathways. J Cell Biochem 109: 726-736, 2010.

12. Mirkheshti N, Park S, Jiang S, Cropper J, Werner SL, Song CS and Chatterjee B: Dual targeting of androgen receptor and mTORC1 by salinomycin in prostate cancer. Oncotarget 7 62240-62254, 2016

13. Li CM, Narayanan R, Lu Y, Hurh E, Coss CC, Barrett CM, Miller DD and Dalton JT: 2-Arylthiazolidine-4-carboxylic acid amides (ATCAA) target dual pathways in cancer cells: 5'-AMP-activated protein kinase (AMPK)/mTOR and PI3K/Akt/ mTOR pathways. Int J Oncol 37: 1023-1030, 2010.

14. Deeb D, Gao X, Dulchavsky SA and Gautam SC: CDDO-me induces apoptosis and inhibits Akt, mTOR and NF-kappaB signaling proteins in prostate cancer cells. Anticancer Res 27: 3035-3044, 2007.

15. Lavie D: The functional groupings of alpha-elaterin (cucurbitacin E). J Pharm Pharmacol 10: 782, 1958.

16. Hsu YC, Huang TY and Chen MJ: Therapeutic ROS targeting of GADD45 $\gamma$ in the induction of G2/M arrest in primary human colorectal cancer cell lines by cucurbitacin E. Cell Death Dis 5: e1198, 2014.
17. Yan $\mathrm{M}$, Zhu $\mathrm{L}$ and Yang Q: Infection of porcine circovirus 2 (PCV2) in intestinal porcine epithelial cell line (IPEC-J2) and interaction between PCV2 and IPEC-J2 microfilaments. Virol J 11: 193, 2014.

18. Huang WW, Yang JS, Lin MW, Chen PY, Chiou SM, Chueh FS, Lan YH, Pai SJ, Tsuzuki M, Ho WJ and Chung JG: Cucurbitacin E Induces G(2)/M Phase Arrest through STAT3/p53/p21 signaling and provokes apoptosis via Fas/CD95 and mitochondria-dependent pathways in human bladder cancer T24 cells. Evid Based Complement Alternat Med 2012: 952762, 2012

19. Li J, Xiong M, Nadavaluru PR, Zuo W, Ye JH, Eloy JD and Bekker A: Dexmedetomidine attenuates neurotoxicity induced by prenatal propofol exposure. J Neurosurg Anesthesiol 28: 51-64, 2016.

20. Henning SM, Wang P, Said JW, Huang M, Grogan T, Elashoff D, Carpenter CL, Heber D and Aronson WJ: Randomized clinical trial of brewed green and black tea in men with prostate cancer prior to prostatectomy. Prostate 75: 550-559, 2015.

21. Kong Y,Chen J,Zhou Z,Xia H, Qiu MH and Chen C: Cucurbitacin $\mathrm{E}$ induces cell cycle $\mathrm{G} 2 / \mathrm{M}$ phase arrest and apoptosis in triple negative breast cancer. PLoS One 9: e103760, 2014.

22. Duncan KL, Duncan MD, Alley MC and Sausville EA: Cucurbitacin E-induced disruption of the actin and vimentin cytoskeleton in prostate carcinoma cells. Biochem Pharmacol 52: 1553-1560, 1996 .

23. Shan XL, Zhou XY, Yang J, Wang YL, Deng YH and Zhang MX: Inhibitory effect of cucurbitacin $\mathrm{E}$ on the proliferation of ovarian cancer cells and its mechanism. Chin J Cancer 29: 20-24, 2010 (In Chinese).

24. Nakashima S, Matsuda H, Kurume A, Oda Y, Nakamura S, Yamashita $\mathrm{M}$ and Yoshikawa $\mathrm{M}$ : Cucurbitacin $\mathrm{E}$ as a new inhibitor of cofilin phosphorylation in human leukemia U937 cells. Bioorg Med Chem Lett 20: 2994-2997, 2010.

25. Lu W and Li Y: Salinomycin suppresses LRP6 expression and inhibits both Wnt/ $\beta$-catenin and mTORC1 signaling in breast and prostate cancer cells. J Cell Biochem 115: 1799-1807, 2014.

26. Yun SM, Jung JH, Jeong SJ, Sohn EJ, Kim B and Kim SH: Tanshinone IIA induces autophagic cell death via activation of AMPK and ERK and inhibition of mTOR and p70 S6K in KBM-5 leukemia cells. Phytother Res 28: 458-464, 2014.

27. Brown RE, Zotalis G, Zhang PL and Zhao B: Morphoproteomic confirmation of a constitutively activated mTOR pathway in high grade prostatic intraepithelial neoplasia and prostate cancer. Int J Clin Exp Pathol 1: 333-342, 2008.

28. Evren S, Dermen A, Lockwood G, Fleshner N and Sweet J: Immunohistochemical examination of the mTORC1 pathway in high grade prostatic intraepithelial neoplasia (HGPIN) and prostatic adenocarcinomas (PCa): A tissue microarray study (TMA). Prostate 70: 1429-1436, 2010.

29. Zha QB, Zhang XY, Lin QR, Xu LH, Zhao GX, Pan H, Zhou D, Ouyang DY, Liu ZH and He XH: Cucurbitacin E Induces Autophagy via downregulating $\mathrm{mTORC1}$ signaling and upregulating AMPK activity. PLoS One 10: e0124355, 2015.

30. Han MA, Min KJ, Woo SM, Seo BR and Kwon TK: Eupafolin enhances TRAIL-mediated apoptosis through cathepsin S-induced down-regulation of Mcl-1 expression and AMPK-mediated Bim up-regulation in renal carcinoma Caki cells. Oncotarget 7: 65707-65720, 2016.

31. Sun C, Zhang M, Shan X, Zhou X, Yang J, Wang Y, Li-Ling J and Deng Y: Inhibitory effect of cucurbitacin E on pancreatic cancer cells growth via STAT3 signaling. J Cancer Res Clin Oncol 136: 603-610, 2010 . 